\title{
An acoustic study on non-local anticipatory effects of Italian length contrast
}

\author{
Giuseppina Turco ${ }^{\text {a) }}$ \\ Laboratoire de Phonétique et Phonologie (UMR 7018) CNRS/Université Sorbonne Nouvelle, \\ 19 rue des Bernardins, 75005, Paris, France \\ Bettina Braun \\ Universität Konstanz, Department of Linguistics, Universitätsstraße 10, Konstanz, 78457, Germany
}

\begin{abstract}
The present study investigates non-local temporal adjustments before an upcoming length contrast in Italian minimal pairs that differ only in the length of the medial consonant (e.g., geminate word palla "ball" vs singleton word pala "shovel"). This contrast is reportedly signaled by the duration of the singleton/geminate consonant and of the preceding vowel. Here, it is shown that the duration adjustment extends further to the word-initial consonant, e.g., the [p] in palla is significantly longer than that in pala (experiment 1). In experiment 2, an effect of syllable structure is ruled out, an unavoidable confound when comparing singleton and geminate words. The comparison of geminate words with cluster words (e.g., as palco "stage"), both of which have a closed first syllable, shows a similar lengthening. Implications for models of speech production are discussed.
\end{abstract}

[http://dx.doi.org/10.1121/1.4962982]

\section{INTRODUCTION}

It is well established that word-initial consonants are lengthened in certain prosodic positions. For instance, in a number of languages, stops are produced with longer voice onset time (VOT) or closure duration in domain-initial position compared to domain-medial position (e.g., Pierrehumbert and Talkin, 1992; Jun, 1993; Hsu and Jun, 1996; Cho and Jun, 2000; Keating et al., 2003; Onaka, 2003).

In the literature, we find accidental reports of a further kind of word-initial lengthening (accidental in the sense that the findings appear to be by-products of a different research question). A word that contains a geminate in medial position (henceforth "geminate word" such as the Japanese word kitte "postal stamps," cf. Han, 1994) is produced with a longer word-initial consonant than an otherwise identical string of sounds that contains a singleton in that position ("singleton word" such as kite "listen"). This kind of lengthening has been reported in Han (1994) and Idemaru and Guion (2008) for Japanese voiceless stops and fricatives, and in Ohala (2007) for Hindi stops. The duration differences are typically small (between 8 and $11 \mathrm{~ms}$ ), at least compared to the domain-initial strengthening effects quoted above (with duration differences between word-initial position and intonational phrase initial position of on average $60 \mathrm{~ms}$ as, for instance, in Japanese; Onaka, 2003). The small effect size may be one of the reasons why this lengthening has not been studied further or discussed systematically yet. However, the initial lengthening differences in those studies appear to be consistent (i.e., they are statistically significant) and are hence not coincidental.

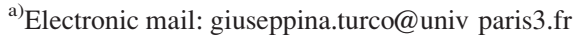

The first goal of this study is to replicate the word-initial lengthening for Italian, a language in which, like Japanese and Hindi, duration is the primary acoustic correlate of the geminate-singleton contrast (Esposito and Di Benedetto, 1999; Pickett et al., 1999; Payne, 2005). To this end, in experiment 1, we will first investigate the duration of wordinitial consonants in disyllabic geminate vs singleton words (e.g., palla vs pala). The word pairs were matched for lexical frequency, a factor that has been shown to strongly influence segment durations (Pluymaekers et al., 2005). To create a strong test case, we included variation by using a varied set of word-initial and word-medial consonants, as well as speakers from different Italian regions (some of which are said to encode the length contrast more consistently than others, cf. Bertinetto and Loporcaro, 2005).

The second goal is to investigate the mechanism behind the effect. We see two plausible explanations that could account for longer word-initial consonants in geminate compared to singleton words. The lengthening may either be caused by the upcoming length contrast ("gemination account") or by differences in syllable type ("syllable account"), since the first syllable is open in singleton words and closed in geminate words (cf. Gili Fivela and Zmarich, 2005). In other words, it is typically assumed that the [1] in palla closes the first syllable and starts the second syllable (Loporcaro, 1990), while the [1] in pala constitutes only the onset of the second syllable.

What speaks in favour of the gemination account is that there are other kinds of coarticulatory effects that span longer domains and manifest themselves on non-adjacent sounds. For instance, there are well-known phenomena such as vowel-to-vowel coarticulation (e.g., Öhman, 1966), labialization (e.g., Benguerel and Cowan, 1974), and nasalization (Moll and Daniloff, 1971), but also less well understood 
durational and spectral adjustments caused by non-adjacent voicing contrasts (e.g., Hawkins and Nguyen, 2004). Note that these studies mostly show non-local adjustments in supralaryngeal articulation, while the gemination account predicts adjustments in the temporal/rhythmic domain. For the listener, the lengthening of word-initial consonants in geminate words may serve as a first indication for the upcoming geminate consonant, hence enhancing and phonetically maximizing the linguistic contrast (e.g., Beckman, 1996; Cho and Jun, 2000). As such, the word-initial lengthening would have a similar function to that of the prosodically conditioned lengthening (or, prosodic strengthening) discussed above: the phonetic correlates of certain phonemic distinctions are maximized by the speaker in order to increase its acoustic (and possibly perceptual) salience (Cho et al., 2007).

The syllable account is supported by speech production models, which often see the syllable as basic planning unit (cf. Cholin and Levelt, 2009; Levelt, 1999). More importantly, open syllables are much more frequent in the languages of the world than closed syllables (Maddieson, 2013). Considering that frequent syllables are named faster or tend to show shorter duration than low frequent syllables (Levelt and Wheeldon, 1994; Benner et al., 2007; Cholin and Levelt, 2009), the observed word-initial lengthening in geminate words may be a by-product of the lower frequency of closed syllables compared to open syllables.

In experiment 2 we probe the syllable account by controlling syllable structure: specifically, we compare the duration of word-initial consonants in geminate and nongeminate words by using closed syllables in both conditions (geminate word: palla vs cluster word: palco "stage"). If geminate words have longer initial consonants than cluster words, an explanation based on syllable structure is unlikely.

\section{EXPERIMENT 1}

\section{A. Methods}

\section{Materials}

Twenty-two Italian minimal pairs with a geminatesingleton contrast in word-medial position were selected as targets (e.g., pappa vs papa, see Table III in Appendix A). On the basis of previous findings, we chose words with a trochaic stress pattern (strong-weak) and with a single consonant in the onset. The word pairs did not differ in lexical frequency as a group: the mean frequency for singleton words was 26.48 occurrences per million (o.p.m. henceforth; standard deviation, $\mathrm{SD}=44.68$ ), for geminate words 37.26 o.p.m. $(\mathrm{SD}=72.95)$ as extracted from the corpus Lessico di frequenza dell' italiano parlato (LIP, http://badip.uni-graz.at/en/).

A further set of 96 words was selected to serve as fillers, so that the presence of the minimal pairs was not too obvious. All fillers were common Italian words that differed in lexical stress placement and number of syllables (16 monosyllabic words and 80 polysyllabic words). Of the 80 polysyllabic filler items, half were trisyllabic (20 with geminates in different positions of the word) and half were 4-syllabic (20 with geminates in different positions).
All words were embedded in a carrier sentence, which was likely to be produced as two prosodic phrases, with a phrase break after the target word: la parola <target $>$, questo è quello che dico ("the word $<$ target $>$, this is what I am saying"). With this kind of prosodic phrasing, the typical realization puts the target word in phrase-final position so that we can minimize instances with a phrase break before the target word (and hence exclude effects based on different levels of prosodic phrasing).

\section{Participants}

Nine Italian native speakers (six female, three male, average age $=28.3 \mathrm{yr}, \mathrm{SD}=4.2$ ) took part in the study for a small monetary award. Participants originated from different parts of Italy, four speakers from Northern Italy, two from the Central area, and three from Southern Italy (see Table IV in Appendix A for more details). All participants had been living in Konstanz (Germany) at the time of testing. They spoke German and English in addition to their native language Italian, but used Italian regularly. None of them was aware of the purpose of the experiment.

\section{Procedure}

The order of the stimuli was pseudo-randomized, with the constraint that two members of a minimal pair were separated by at least ten other words. The reading list started with two filler items to familiarize participants with the task. The number of geminate and singleton words was balanced across the first and second half of the experiment.

Each participant was recorded in the Phonetic Laboratory at the University of Konstanz (Germany). The productions were recorded digitally using an Olympus 24 bit digital wave/ MP3 recorder and by an AKG GHS 1 Gaming headset microphone (44.1 kHz,16 Bit).

Participants were tested individually. They were instructed in Italian by an Italian native speaker to read each sentence aloud at normal speed. In the rare case of hesitations or disfluencies, they were asked to repeat the respective sentence(s) at the end of the session. The whole recording session lasted $15 \mathrm{~min}$ on average.

\section{Analysis}

The recordings were first annotated on the word level, and for each target word, the segments (closure duration in the case of stops and consonant duration for other consonants). Furthermore, we annotated the syllable pa in parola. Annotations were done according to the segmentation procedure by Turk et al. (2006). Specifically, when C1 was a stop consonant, the stop closure duration was measured from the offset of the previous vowel (i.e., the last glottal pulse with continuous F2 of the last vowel [a] of parola; see Figs. 1 3) to the onset of the burst or the onset of voiceless aspiration (in cases in which there was no visible burst). For fricatives, the start and the end points were set at the onset and offset of the friction noise. Spectral changes guided the segmentation in more problematic cases of breathiness and aspiration before and after the frication noise. Finally, for nasals, the 
(a)
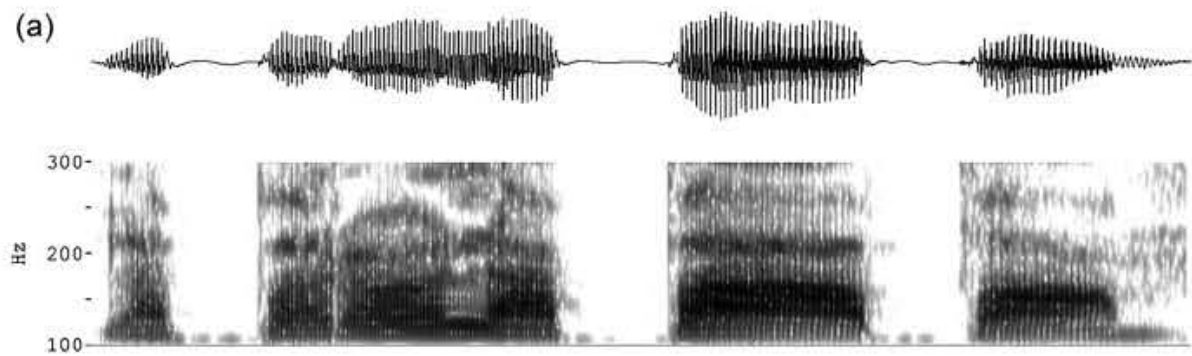

\begin{tabular}{|c|c|c|c|c|c|}
\hline & \multirow[t]{2}{*}{ parola } & \multicolumn{4}{|c|}{ papa } \\
\hline pa & & $p$ & a & $p$ & $a$ \\
\hline & & $\mathrm{C} 1$ & $\mathrm{v} 1$ & $\mathrm{C} 2$ & $\mathrm{v} 2$ \\
\hline & & 0 & & 0 & \\
\hline
\end{tabular}

(b)

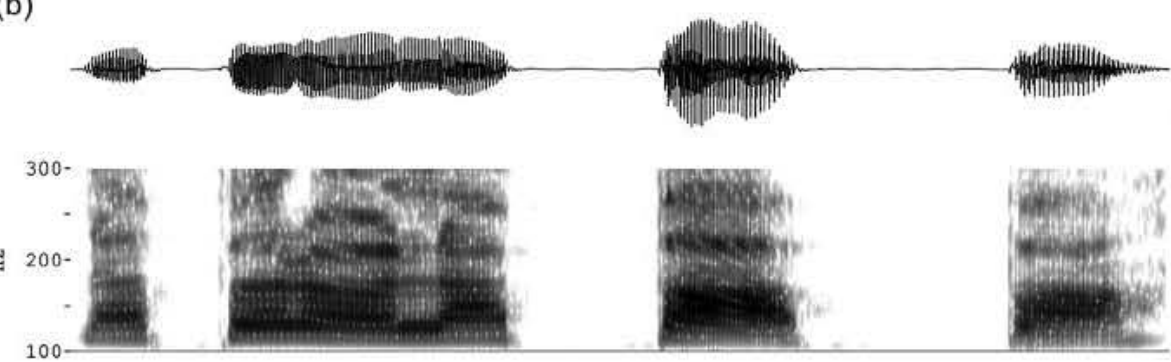

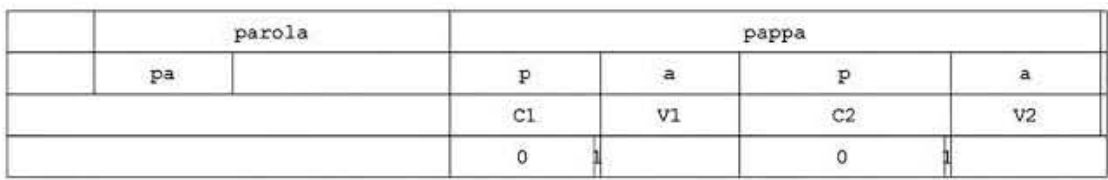

(a)
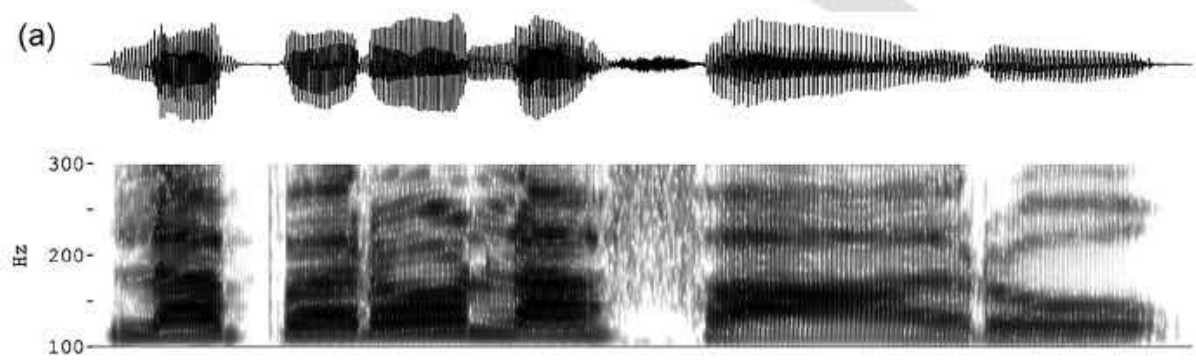

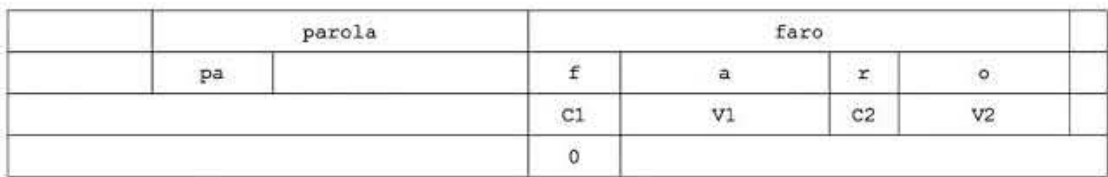

(b)
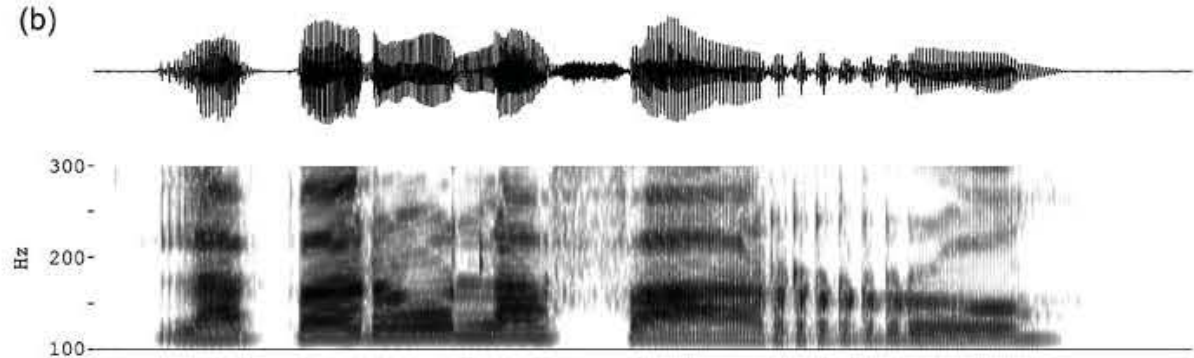

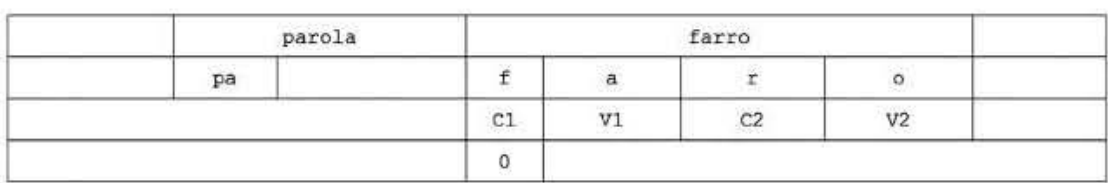

FIG. 1. Waveform and spectrogram of the Italian words papa "pope" (top) and pappa "baby food" (bottom). C1 represents the initial consonant " " 0 " is the closure duration and " 1 " is the VOT of the [p]), V1 is the first vowel, $\mathrm{C} 2$ is the medial consonant, and V2 is the final vowel.

FIG. 2. Waveform and spectrogram of the Italian words faro "head lamp" (top) and farro "hulled wheat" (bot tom). $\mathrm{C} 1$ represents the initial conso nant " 0 " is the consonant duration [f]), $\mathrm{V} 1$ is the first vowel, $\mathrm{C} 2$ is the medial consonant, and V2 is the final vowel. 
(a)
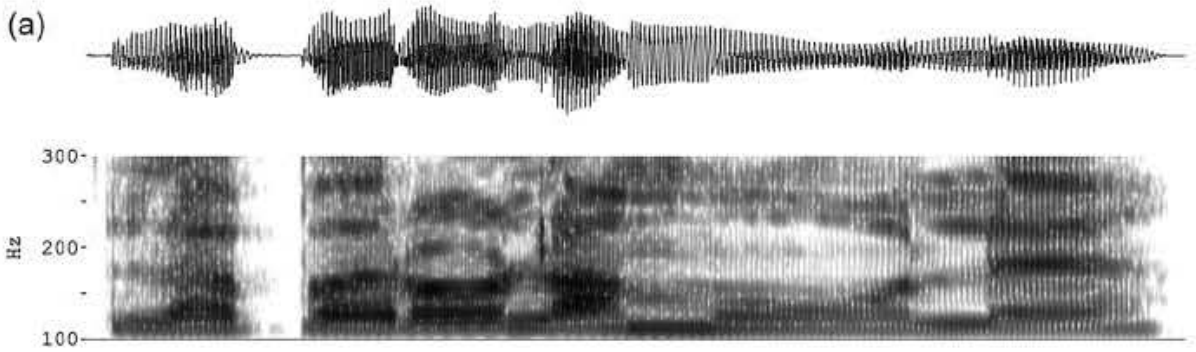

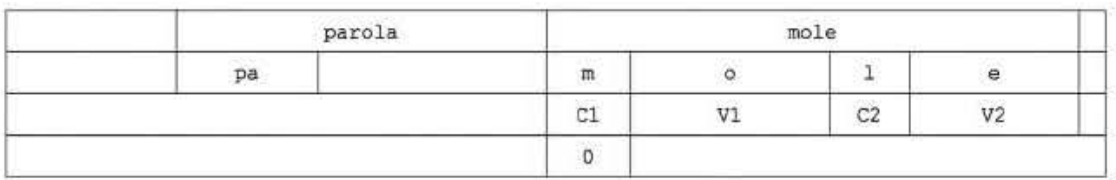

(b)
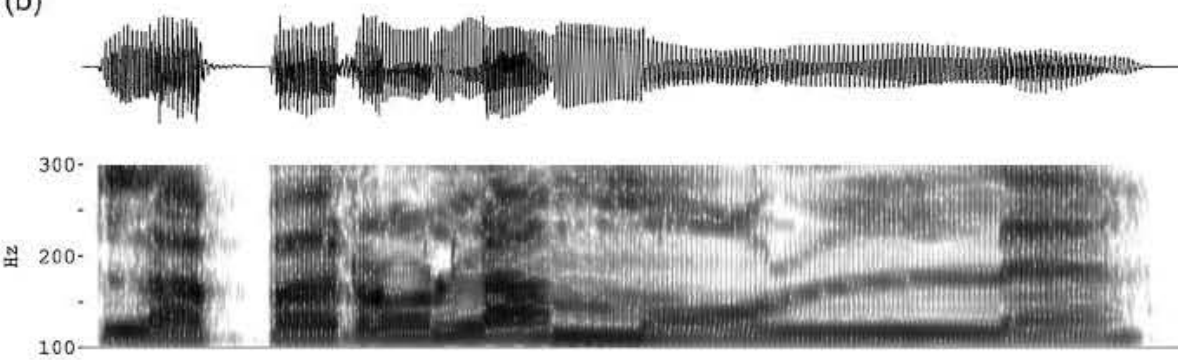

FIG. 3. Waveform and spectrogram of the Italian words mole "millstone" (top) and molle "springs" (bottom). $\mathrm{Cl}$ represents the initial consonant (" 0 " is the consonant duration [m]), V1 is the first vowel, $\mathrm{C} 2$ is the medial con sonant, and V2 is the final vowel.

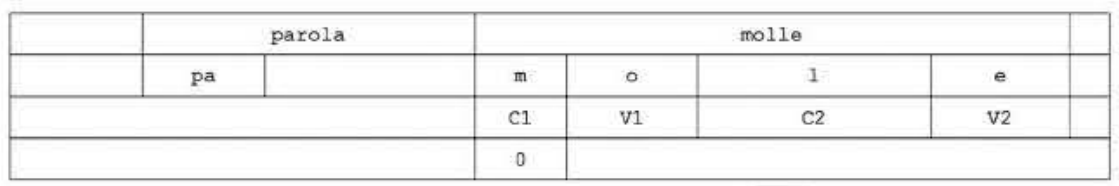

segmentation was guided by abrupt spectral changes. All landmarks were set using the waveform, which has a higher resolution than the broadband spectrogram. To ensure labeling accuracy, 144 of the 396 target words (in particular nasals) were annotated by a second annotator who was unaware of the purpose of the experiment (a native speaker of German, trained in phonetics and acoustic annotation). The duration difference between the two annotators was $2 \mathrm{~ms}$ on average $(\mathrm{SD}=0.25)$, which suggests a highly reliable annotation. For the statistical analyses, the annotations of the native speaker (the first author) were used.

From these annotations, we extracted the raw duration of the word-initial consonant (C1), the first vowel (V1), and the second consonant $(\mathrm{C} 2)$. Furthermore, to control for speaking rate differences, we normalized the raw duration of $\mathrm{Cl}$ by computing the ratio of its duration to the duration of the preceding word parola (cf. Picket et al., 1999).

\section{B. Results}

The measurements of the 396 items ( 9 speakers $\times 22$ geminate-singleton pairs) were first screened for outliers to avoid skewing of the data. Data points beyond 2.5 standard deviations above or below the mean of each speaker were inspected again $(n=10)$. All of these outliers had a phrase break before the target word or a mispronunciation in either the word parola or the target word and were therefore excluded from the analysis. The remaining 190 singleton words (95.9\% of the data) and 196 geminate words (98.9\% of the data) were analyzed in the following way. We calculated linear-mixed effects regression models with raw and normalized duration of $\mathrm{C} 1$ as dependent variables, respectively, and condition (singleton vs geminate) as fixed factor. Speaker and item were entered as crossed-random factors, (allowing for by-participant and by-item adjustments for intercepts and slopes) (Cunnings, 2012). All models further included item-specific control predictors that have been shown to affect segment durations, namely, log-lexical frequency and position of the target word in the reading list. $p$-values were calculated on the basis of Satterthwaite approximation of degrees of freedom in the lmerTest package (Kuznetsova, 2013). The control predictors were not significant (all $p$-values $>0.4$ ) in any of the models and were therefore removed ("backward elimination" procedure, cf. Baayen, 2008). In the description of the results, they are not reported.

Since the acoustic realization of the geminate-singleton contrast is argued to differ across varieties of Italian, we first ensured that all participants realized the consonantal length contrast by comparing the duration of the wordmedial consonant $(\mathrm{C} 2)$ and the immediately preceding vowel (V1) across conditions. As Table IV in Appendix A shows, the contrast is consistently realized by each speaker (C1, average differences between $1.9 \mathrm{~ms}$ and $28.1 \mathrm{~ms}$; see also Table $\mathrm{V}$ for differences in initial lengthening by manner of articulation).

Table I reports the average and mean values of the dependent variables across conditions; the speaker-specific values are presented in Appendix A (Table IV). 
TABLE I. Mean values, standard deviations (SD), and $p$ values of the aver age raw duration of the initial consonant $(\mathrm{C} 1)$ and the average duration ratio between the $\mathrm{C} 1$ and the preceding word parola in Italian singleton geminate minimal pairs.

\begin{tabular}{lccccccc}
\hline \hline & \multicolumn{2}{c}{ Singleton } & & \multicolumn{2}{c}{ Geminate } & \\
\cline { 2 - 3 } Duration/Condition & Mean & SD & & Mean & SD & & $p$ value \\
\hline C1 duration (ms) & 89.1 & 26.8 & & 97.8 & 31.4 & 0.013 \\
Ratio of C1 duration/parola & 0.315 & 0.097 & & 0.352 & 0.11 & 0.004 \\
\hline \hline
\end{tabular}

The duration of $\mathrm{C} 1$ was significantly shorter in geminate than in singleton words $\left[\beta_{\text {singleton }}=-9.07\right.$, standard error $(\mathrm{SE})=2.89, t=-3.13, p=0.013] .{ }^{1}$ This was also the case for the normalized duration of $\mathrm{C} 1$ (duration ratio of $\mathrm{C} 1$ / parola): $\beta_{\text {singleton }}=-0.04, \mathrm{SE}=0.01, t=-3.72, p=0.004$, suggesting that potential differences in speaking rate do not affect the results. Following the suggestion of an anonymous reviewer, we used another test to exclude speaking rate differences. We investigated whether another syllable in the utterance (here, the syllable pa of parola, which is easy to segment and in the same phrase) was influenced by condition as well. If it were, the alleged effect of condition would actually be an effect of speaking rate. On the other hand, if there were no effect of condition on the duration of the syllable $p a$, it would be unlikely that the lengthening of $\mathrm{C} 1$ in geminate words is caused by differences in speaking rate. Our results showed no effect of condition on the duration of the syllable $p a(p=0.3)$, and, when combining the duration measures of $p a$ and $\mathrm{C} 1$, there was a significant interaction between measurement unit (control syllable $p a$ vs C1-duration) and condition $(\beta=10.57, \mathrm{SE}=2.95, \quad t=3.58$, $p=0.0004)$. This allowed us to conclude that the observed lengthening in geminate words is not due to differences in speaking rate.

Since the absolute duration difference across conditions is rather small (on average $9 \mathrm{~ms}$ ), we ran a number of control analyses to challenge the finding. First, to exclude that undetected pauses in word-initial stops of geminate words increased C1 duration, we calculated an additional model with only word-initial nasals and fricatives (for which pauses are obvious in the signal). The model revealed a similar effect of condition on $\mathrm{C} 1$ duration $\left(\beta_{\text {singleton }}=-6.76\right.$, $\mathrm{SE}=2.33, t=-2.89, p=0.01)$ and on the duration ratio $\mathrm{C} 1 /$ parola $\quad\left(\beta_{\text {singleton }}=-0.02, \quad \mathrm{SE}=0.01, \quad t=-2.61\right.$, $p=0.02)$. Second, to further rule out possible word frequency confounds (i.e., geminate words were slightly more frequent than singleton words), we calculated an additional model that only contained seven minimal pairs (124 observations overall) for which lexical frequency was completely matched for each pair (average difference across pairs: 2.57 , $\mathrm{SD}=1.12$, mean singleton: $2.27, \mathrm{SD}=1.29$, mean geminate $=2.85, \mathrm{SD}=1.75)$. The analysis also showed a significant effect of condition $\left(\beta_{\text {singleton }}=-10.90, \mathrm{SE}=2.81\right.$, $t=-3.87, p=0.004)$.

\section{Discussion}

Experiment 1 showed longer durations of the wordinitial consonant in geminate words than in singleton words henceforth called non-local gemination effect. This non-local gemination effect is small (on average $9 \mathrm{~ms}$ ) but consistent. Expressed in proportional terms, the gemination effect is not negligible. After all, the word-initial consonant is lengthened by about $10 \%$ in geminate compared to singleton words. Control analyses excluded the possibility that the lengthening is due to effects of speaking rate or lexical frequency.

Our data show word-initial lengthening for Italian, a language that is characterized by differences in the phonetic realization of the geminate-singleton contrast across dialects. Our speakers all realized the geminate-singleton contrast by means of temporal adjustment of the consonant in question (C2), the vowel preceding the length contrast (V1), and also the word-initial consonants $(\mathrm{C} 1)$. These results provide a further instance of temporal adjustments beyond the immediately preceding vowel (V1), a phenomenon that has been established for Italian in other studies (e.g., Esposito and Di Benedetto, 1999; Pickett et al., 1999). What we show is that the temporal adjustments extend to non-adjacent word-initial consonant, in line with reports on other languages, such as Japanese and Hindi (Han, 1994; Ohala, 2007; Idemaru and Guion, 2008). Some languages report a non-local gemination effect in the opposite direction (Local and Simpson, 1999), which suggests language-specific articulatory mechanisms.

Unlike previous studies, we used a more varied set of consonants in word-initial and word-medial position, which allows us to better generalize the finding. Interestingly, the word-initial consonantal lengthening (C1) goes in the opposite direction to the temporal adjustment in the first vowel (V1) but in the same direction as the duration of the wordmedial consonant (which hosts the phonological length contrast). The length contrast in the word-medial consonant is hence anticipated in the segments preceding the length contrast in a different way. It may be speculated whether or not these non-local adjustments serve to enhance the upcoming length contrast and assist spoken word recognition, as previously shown for other small but systematic temporal adjustments (West, 1999; Heid and Hawkins, 2000; Hawkins and Nguyen, 2003).

Experiment 2 was designed to test (and to rule out) differences in syllable structure as a possible mechanism for the temporal adjustment observed here (open first syllable in singleton vs closed first syllable in geminate words). We hence compared the durational structure in word pairs with word-medial consonant clusters and geminates (e.g., [p] in panda vs panna).

\section{EXPERIMENT 2}

\section{A. Methods}

\section{Material}

Twenty-four trochaic word pairs containing a consonant cluster or geminate in medial position, respectively (e.g., palco and palla), were selected as targets. Apart from the geminate vs cluster, the words were identical (except for rare cases in which the final vowel differed). The cluster always started with the same place and manner of articulation and 
the same voicing specification as the geminate consonant. Due to the constraint of finding matching cluster words, the geminate words were partly different from those used in experiment 1 (see Table VI in Appendix B for the full list of items). The minimal pairs were matched for lexical frequency (25.72 o.p.m., $\mathrm{SD}=31.28$, for cluster words vs 24.10 o.p.m., $\mathrm{SD}=41.98$, for geminate words), based on the LIP corpus (cf. Sec. II). The fillers were the same as in experiment 1.

\section{Participants}

Nine Italian participants, different from those in experiment 1 but from the same population, took part for a small monetary award (six female, three male, age average $=30 \mathrm{yr}$, $\mathrm{SD}=5.1$ ). As in experiment 1 , they originated from different parts of Italy (cf. Table VII in Appendix B) but had been living in Konstanz at the time of testing. None of them was aware of the purpose of the experiment.

\section{Procedure}

The procedure, labeling criteria, measurements, and statistical analyses were the same as in experiment 1 .

\section{B. Results}

Employing the same criteria as in experiment 1, we discarded 15 of the 432 tokens because the target word was preceded by a pause. This left 417 data points for analysis (207 cluster words and 210 geminate words, accounting for $95.8 \%$ of the cluster data and $97.2 \%$ of the geminate data).

Table II shows the average duration of $\mathrm{C} 1$ and the duration ratio $\mathrm{C} 1 /$ parola across conditions (see Table VII in Appendix $\mathrm{B}$ for duration of $\mathrm{C} 1$ and $\mathrm{V} 1$, and $\mathrm{C} 2$, broken down by speaker).

Similar to experiment 1 , the duration of $\mathrm{C} 1$ was significantly longer in geminate than in cluster words, both in terms of raw segment duration $\left(\beta_{\text {cluster }}=-10.77, \mathrm{SE}=2.14\right.$, $t=-5.02, p=0.0001)$ and normalized duration $\left(\beta_{\text {cluster }}\right.$ $=-0.04, \mathrm{SE}=0.00, t=-5.50, p<0.0001)$. The results hence did not seem to be caused by differences in speaking rate. The control syllable $p a$ from parola was not affected by condition $(p=0.8)$ and there was a significant interaction between measurement unit ( $p a$ vs $\mathrm{C} 1$ ) and condition $(\beta=12.71, \mathrm{SE}=3.24, t=3.91, p<0.0001)$.

In addition, the results were the same when excluding words starting with stops (C1 duration: $\beta_{\text {cluster }}=-10.90$, $\mathrm{SE}=2.72, t=-4.00, p=0.003, \mathrm{C} 1 /$ parola $: \beta_{\text {cluster }}=-0.03$, $\mathrm{SE}=0.01, t=-2.96, p=0.016)$. Also, the results did not

TABLE II. Mean values, standard deviations, and $p$ values of the average raw duration of the initial consonant $(\mathrm{C} 1)$ and the average duration ratio between the $\mathrm{C} 1$ and the preceding word parola in Italian cluster geminate word pairs.

\begin{tabular}{lccccccc}
\hline \hline & \multicolumn{2}{c}{ Cluster } & & \multicolumn{2}{c}{ Geminate } & \\
\cline { 2 - 3 } Duration/Condition & Mean & SD & & Mean & SD & & $p$ value \\
\hline C1 duration (ms) & 85.5 & 27.9 & & 96.2 & 28.9 & 0.0001 \\
Ratio of C1 duration/parola & 0.301 & 0.099 & & 0.337 & 0.103 & 0.0001 \\
\hline \hline
\end{tabular}

change when only the word pairs with the same lexical frequency for each pair were tested (eight minimal pairs, with average difference across pairs $=2.95, \mathrm{SD}=1.47$, mean cluster $=2.38, \mathrm{SD}=1.97$, mean geminate $=3.20, \mathrm{SD}=1.59)$ : $\beta_{\text {cluster }}=-8.79, \mathrm{SE}=3.20, t=-2.74, p=0.009$ (C1 duration); $\beta_{\text {cluster }}=-0.02, \mathrm{SE}=0.01, t=-2.59, p=0.01(\mathrm{C} 1 /$ ratio $)$.

\section{Discussion}

Experiment 2 shows longer durations of the word-initial consonants in geminate words than in cluster words. Unlike in experiment 1 , both conditions contain words whose first syllable is closed (i.e., has a consonant after the vowel) and which do not differ in terms of number of timing units (Gili Fivela and Zmarich, 2005, for experimental evidence; Loporcaro, 1990). This result strongly suggests that the gemination effect is not solely reducible to difference in syllable structure between singleton and geminate words (open vs closed syllable) but represents a genuine effect of gemination. Further analyses allow us to exclude effects of lexical frequency and speaking rate. Note that experiment 2 tested a different set of speakers, also from different areas of Italy. Nevertheless all speakers consistently lengthened the first consonant in geminate compared to cluster words.

\section{GENERAL DISCUSSION AND CONCLUSION}

The main finding of our production data is that wordinitial consonants in disyllabic geminate words (e.g., [p] in palla "ball") are produced with a longer duration than wordinitial consonants in singleton words (e.g., [p] in pala "shovel," cf. experiment 1) and cluster words (e.g., [p] in palco "stage," cf. experiment 2). Unlike previous studies that reported word-initial lengthening in geminate words compared to singleton words (Han, 1994; Ohala, 2007; Idemaru and Guion, 2008), we included a more varied set of consonant types in word-initial and word-medial positions, and used a heterogeneous group of speakers (from different Italian varieties). Despite reported variation in the realization of the length contrast between Northern, Central-Southern, and Tuscany Italian speakers (cf. Bertinetto and Loporcaro, 2005), all speakers produced the length contrast in wordmedial position (see Table IV in Appendix A) by longer duration in geminate compared to singleton words and, more importantly for the current study, by longer duration of the word-initial consonant. The direction of the effect is in line with previous observations on lengthening of word-initial stops and fricatives in Japanese (Han, 1994; Idemaru and Guion, 2008), and of stops in Hindi (Ohala, 2007). Note that the current investigation focused on those acoustic properties that have been reported to be the primary cue for the consonantal length contrast in Italian: the (raw) closure duration for stops and overall consonant duration for nasals and fricatives (Esposito and Di Benedetto, 1999; Pickett et al., 1999; Payne, 2005). In future studies, we would like to focus on other articulatory properties of the word-initial consonant to test whether the increase in duration is accompanied by increases in intensity or articulatory precision. Specifically, it is expected that the observed initial lengthening may be accompanied with an increased linguo-palatal contact, as 
observed for initial articulatory strengthening as induced by higher-order prosodic domains (e.g., Fougeron and Keating, 1997).

Our experiments crucially extend prior findings by showing that the duration differences in the word-initial consonant between geminate and singleton words cannot be explained by differences in syllable structure. Irrespective of whether the first syllable in the non-geminate words was open (singleton words in experiment 1 ) or closed (cluster words in experiment 2), word-initial consonants are shorter here than in geminate words. Hence, what really counts for the articulation of the word-initial consonant is whether there is a wordmedial geminate consonant or not, despite considerable variation in the type of initial and medial consonant and speaker.

This finding hence provides an instance of a non-local temporal influence, from the duration of the word-medial consonant to the word-initial consonant, across an intervening vowel (V1), which is temporally adjusted in the opposite direction. Note that an alternative account, predicting that the lengthening of the word-initial consonant might also be caused by the duration of the preceding vowel (V1) is unlikely for two reasons. First, in languages with a vowel length contrast (German /'ratə/ "rat" vs /'ra:tə/ "rate"), C1 is not affected by differences in vowel length (Turco and Braun, 2014). Second, the differences in vowel duration between cluster and geminate words is not statistically significant (compared to geminate vs singleton words; see also Gili Fivela and Zmarich, 2005), but the gemination effect is numerically slightly larger in experiment 2 (comparing cluster and geminate words) than in experiment 1 (comparing singleton and geminate words).

The lengthening of the word-initial consonant found here is phonetic in nature and hence not comparable, in qualitative and quantitative terms, to cases of post-lexical initial gemination (raddoppiamento sintattico) in Italian (i.e., a process by which the initial consonant is lengthened after words that end with a stressed vowel as in virtù [d:]iversa, "different virtue," e.g., Nespor and Vogel, 1986; Payne, 2005, for experimental evidence). What we do not know is whether the gemination effect on the duration of the word-initial consonant is comparable to the prosodic strengthening effect since there are no data on Italian. Possibly, speakers are able to signal both prosodic hierarchy (e.g., Pierrehumbert and Talkin, 1992; Jun, 1993; Hsu and Jun, 1996; Cho and Jun, 2000; Keating et al., 2003; Onaka, 2003; Cho, 2004) and word-based rhythmic properties (the gemination effect reported here) by encoding finegrained phonetic differences. These processes may interact and conceivably, the gemination effect is even larger at the start of higher prosodic domains compared to the phrasemedial position that we tested here.

This study adds to the body of research on non-local adjustments for other properties (e.g., Benguerel and Cowan, 1974, for labialization; Moll and Daniloff, 1971, for nasalization; Öhman, 1966, for vowel-to-vowel coarticulation) and from phonological harmony processes (Nguyen and Fagyal, 2008). Interestingly, there seem to be cross-linguistic differences regarding the occurrence (Hussain, 2015, for Punjabi) and the direction of the lengthening (e.g., for
Malayalam the initial consonant is shortened before a word-medial geminate than a singleton consonant; Local and Simpson, 1999). More cross-linguistic investigations are needed to understand the factors that affect the wordinitial lengthening.

The current findings pose questions concerning the representations of the prosodic units (e.g., syllable, foot, prosodic word) that are built during speech planning. In other words, which representations and processes are necessary to result in the gemination effect reported here? Wordbased representations are well suited as a planning unit (e.g., [panna $]_{\mathrm{w}}$, see Pierrehumbert, 2001; Hawkins, 2003; Bybee, 2006, among others), since the processor knows about the geminate. On the other hand, syllable-sized representations (e.g., [pan $]_{\sigma}[\mathrm{na}]_{\sigma}$, cf. Levelt, 1999) are more efficient and account well for other phenomena, but are only suited when the planning window is wide enough to "see" the geminate. Unfortunately, we are not (yet) in a position to decide between these alternative accounts.

The gemination effects reported here are small, but may be of perceptual relevance. Earlier perception studies have shown that listeners use fine-grained differences in duration and spectral energy for lexical decisions. For instance, Hawkins and Nguyen (2003) found that durational differences (on average $4.2 \mathrm{~ms}$ ) of the onset liquids contributed to the anticipation of coda voicing: longer $/ 1 / \mathrm{s}$ in the syllable onset lead to more responses of a voiced than a voiceless coda. In the future, we will test by means of a visual world paradigm whether listeners are able to anticipate whether a word is a geminate or singleton word based on the duration of the word-initial consonant.

To conclude, in Italian the word-medial geminate is encoded already in the word-initial consonant, which is realized longer than in comparable singleton and cluster words. This gemination effect is numerically small, but consistent, and we showed that it cannot be explained by differences in syllable structure, speaking rate, or lexical frequency. Following previous studies on prosodic strengthening (e.g., Cho and Jun, 2000; Beckman, 1996), this effect may be interpreted as the phonetic manifestation that serves to enhance the upcoming length contrast.

\section{ACKNOWLEDGMENTS}

This research was funded by a research programme and innovation of the European Union Horizon 2020, through a Marie Sklodowska-Curie ${ }^{\circ} 662530$ (GeHa: Gemination Harmony) awarded to G.T. and by an AFF grant on Suprasegmentals awarded to B.B. We would like to thank Verena Heidler for annotating a subset of the data as well as the audience of P\&P10 in Konstanz in 2014, the workshop on Geminate consonants across the world in Glasgow in 2015, and three anonymous reviewers for valuable feedback.

\section{APPENDIX A}

See Tables III $\mathrm{V}$ for a list of stimuli and additional results of experiment 1 . 
TABLE III. List of 22 singleton geminate minimal pairs (experiment 1).

\begin{tabular}{|c|c|c|}
\hline Initial segment & Target items & Translation \\
\hline \multirow[t]{8}{*}{ Stops: /k/ /p/ } & 1. caro carro & expensive wagon \\
\hline & 2. cane canne & dog fishing rods \\
\hline & 3. capa cappa & boss (feminine) extractor fan \\
\hline & 4. calo callo & decrease callus \\
\hline & 5. poro porro & pore leek \\
\hline & 6. pala palla & shovel ball \\
\hline & 7. pena penna & pain pen \\
\hline & 8. papa pappa & pope baby food \\
\hline \multirow[t]{8}{*}{ Nasals: /m//n/ } & 9. note notte & note (plural) night \\
\hline & 10. nana nanna & dwarf (feminine) beddy bye (in child speech) \\
\hline & 11. nona nonna & ninth (feminine) grandmother \\
\hline & 12. nono nonno & ninth (masculine) grandfather \\
\hline & 13. moto motto & motorcycle maxim \\
\hline & 14. mese messe & month Mass (plural) \\
\hline & 15. mole molle & millstone spring (plural) \\
\hline & 16. mora morra & blackberry (type of) Italian popular game \\
\hline \multirow[t]{6}{*}{ Fricatives: /f/ /s/ } & 17. fata fatta & fairy done (feminine) \\
\hline & 18. faro farro & (head)lamp hulled wheat \\
\hline & 19. fumo fummo & smoke (we) were \\
\hline & 20. fuga fugga & escape to escape (subjunctive/imperative form) \\
\hline & 21. sano sanno & sane (they) know \\
\hline & 22. seno senno & breast sense/judgment \\
\hline
\end{tabular}

TABLE IV. Speaker specific mean values and standard deviations of the raw duration of the initial consonant (C1), the first vowel (V1), and the medial conso nant (C2) in Italian singleton geminate minimal pairs. Information on speaker origin is provided in brackets.

\begin{tabular}{|c|c|c|c|c|c|c|}
\hline & \multicolumn{2}{|c|}{$\mathrm{C} 1$} & \multicolumn{2}{|c|}{ V1 } & \multicolumn{2}{|c|}{$\mathrm{C} 2$} \\
\hline & $\begin{array}{l}\text { Singleton } \\
\text { Mean (SD) }\end{array}$ & $\begin{array}{c}\text { Geminate } \\
\text { Mean }(\mathrm{SD})\end{array}$ & $\begin{array}{l}\text { Singleton } \\
\text { Mean (SD) }\end{array}$ & $\begin{array}{c}\text { Geminate } \\
\text { Mean (SD) }\end{array}$ & $\begin{array}{c}\text { Singleton } \\
\text { Mean }(\mathrm{SD})\end{array}$ & $\begin{array}{c}\text { Geminate } \\
\text { Mean (SD) }\end{array}$ \\
\hline Speaker 1 (South: Sicily) & $92.5(26.2)$ & $97.1(22.8)$ & $238.4(36.1)$ & $150.0(28.5)$ & $91.0(28.1)$ & $236.2(35.7)$ \\
\hline Speaker 2 (South: Sicily) & $82.4(27.2)$ & $90.6(27.5)$ & $154.5(23.7)$ & $121.5(19.7)$ & $69.9(22.4)$ & $168.6(31.0)$ \\
\hline Speaker 3 (North: Genoa) & $97.7(25.6)$ & $125.9(29.3)$ & $223.0(31.8)$ & $154.0(26.7)$ & $60.1(28.8)$ & $195.7(28.3)$ \\
\hline Speaker 4 (Centre: Pisa) & $77.0(25.3)$ & $82.1(26.5)$ & $184.1(29.8)$ & $144.6(19.8)$ & $67.7(22.6)$ & $176.2(27.7)$ \\
\hline Speaker 5 (North: Genoa) & $76.1(22.0)$ & $82.8(28.7)$ & $169.8(14.7)$ & $124.3(16.5)$ & $60.6(24.4)$ & $143.8(27.2)$ \\
\hline Speaker 6 (North: Pavia) & $86.3(24.4)$ & $88.2(29.1)$ & $212.3(31.5)$ & $144.5(26.9)$ & 69.8 (31.9) & $183.8(33.4)$ \\
\hline Speaker 7 (Centre: Chieti) & $90.3(20.7)$ & $92.5(24.8)$ & $214.6(29.8)$ & $151.9(26.8)$ & $69.1(27.2)$ & $180.6(24.5)$ \\
\hline Speaker 8 (South:Cosenza) & $84.5(16.3)$ & $91.5(19.2)$ & $195.6(17.8)$ & $141.1(25.9)$ & $72.5(25.8)$ & $168.9(27.6)$ \\
\hline Speaker 9 (North: Pavia) & $116.8(32.1)$ & $132.3(33.3)$ & $183.5(28.7)$ & $120.3(24.2)$ & $87.9(41.7)$ & $225.0(35.9)$ \\
\hline Average & $89.1(26.8)$ & $97.7(31.4)$ & $197.1(37.6)$ & $139.3(26.9)$ & $72.0(29.6)$ & $186.1(40.2)$ \\
\hline
\end{tabular}

TABLE V. Mean values, standard deviations of the average raw duration of the initial consonant (C1) in Italian singleton geminate word pairs split by manner of articulation.

\begin{tabular}{lcccr}
\hline \hline & \multicolumn{2}{c}{ Singleton } & & \multicolumn{2}{c}{ Geminate } \\
\cline { 2 - 5 } Duration/Condition & Mean & SD & Mean & SD \\
\hline Stops $(N \quad 139)$ & 78.4 & 18.7 & 91.0 & 26.7 \\
Fricatives $(N \quad 107)$ & 120.9 & 20.5 & 128.0 & 24.4 \\
Nasals $(N \quad 140)$ & 75.3 & 15.5 & 81.6 & 23.9 \\
\hline
\end{tabular}




\section{APPENDIX B}

See Tables VI and VII for a list of stimuli and additional results of experiment 2.

TABLE VI. List of 24 cluster geminate word pairs (experiment 2).

\begin{tabular}{|c|c|}
\hline Target items & Translation \\
\hline 1. barra barca & slash boat \\
\hline 2. carro carne & wagon meat \\
\hline 3. canne canto & fishing rod (plural) song \\
\hline 4. callo calcio & callus football \\
\hline 5. cappa capra & extractor fan goat \\
\hline 6. cassa casta & case/crate caste \\
\hline 7. fallo falso & fault false \\
\hline 8. ferro fermo & iron custody \\
\hline 8. folla folta & crowd thick \\
\hline 10. gamma gamba & range leg \\
\hline 11. morra morta & (type of) Italian popular game dead (feminine) \\
\hline 12. palla palco & ball stage \\
\hline 13. passo pasto & step meal \\
\hline 14. panna panda & cream panda \\
\hline 15. porro porto & leek harbour \\
\hline 16. pollo polso & chicken wrist \\
\hline 17. pinna pinza & fin pliers \\
\hline 18. sacco sacro & sack sacred \\
\hline 19. sella selva & saddle forest \\
\hline 20. serra serva & greenhouse servant \\
\hline 21. sesso sesto & sex sixth \\
\hline 22. sanno santo & (they) know saint \\
\hline 23. tassa tasca & tax pocket \\
\hline 24. terra terza & ground third (feminine) \\
\hline
\end{tabular}

TABLE VII. Speaker specific mean values and standard deviations of the raw duration of C1, V1, and V2 in Italian cluster geminate word pairs. Information on speaker origin is provided in brackets.

\begin{tabular}{|c|c|c|c|c|c|c|}
\hline & \multicolumn{2}{|c|}{$\mathrm{C} 1$} & \multicolumn{2}{|c|}{ V1 } & \multicolumn{2}{|c|}{$\mathrm{C} 2$} \\
\hline & $\begin{array}{c}\text { Cluster } \\
\text { Mean (SD) }\end{array}$ & $\begin{array}{l}\text { Geminate } \\
\text { Mean }(\mathrm{SD})\end{array}$ & $\begin{array}{c}\text { Cluster } \\
\text { Mean (SD) }\end{array}$ & $\begin{array}{c}\text { Geminate } \\
\text { Mean (SD) }\end{array}$ & $\begin{array}{c}\text { Cluster } \\
\text { Mean (SD) }\end{array}$ & $\begin{array}{c}\text { Geminate } \\
\text { Mean (SD) }\end{array}$ \\
\hline Speaker 1 (South: Cagliari) & $92.1(23.2)$ & $100.2(35.5)$ & $118.3(27.7)$ & $108.3(24.2)$ & $204.9(38.1)$ & $173.0(34.4)$ \\
\hline Speaker 2 (Centre: Rome) & $97.4(28.4)$ & $113.7(29.8)$ & $117.1(24.5)$ & $117.3(23.1)$ & $205.8(39.4)$ & $190.7(23.4)$ \\
\hline Speaker 3 (North: Milan) & $65.5(44.0)$ & $77.6(36.9)$ & $129.2(23.8)$ & $119.0(27.7)$ & $177.4(29.8)$ & $152.0(31.6)$ \\
\hline Speaker 5 (South: Salerno) & $77.8(22.8)$ & $86.8(20.8)$ & $139.2(22.2)$ & $129.0(29.8)$ & $213.8(46.9)$ & $204.7(44.1)$ \\
\hline Speaker 6 (South: Syracuse) & $88.6(34.8)$ & $92.1(22.5)$ & $135.7(23.1)$ & $121.9(30.2)$ & $212.3(44.6)$ & $169.3(43.4)$ \\
\hline Speaker 7 (North: Bergamo) & $99.4(26.5)$ & $111.8(22.0)$ & $158.2(20.4)$ & $136.3(26.1)$ & $180.2(33.6)$ & $151.2(47.7)$ \\
\hline Speaker 8 (Centre: Chieti) & $68.1(23.1)$ & $77.5(29.2)$ & $131.5(26.0)$ & $136.3(24.5)$ & $226.7(45.7)$ & $195.5(31.6)$ \\
\hline Speaker 9 (Centre: Chieti) & $89.7(23.0)$ & $100.4(29.8)$ & $125.5(25.3)$ & $125.5(25.6)$ & $245.8(44.9)$ & $202.6(40.3)$ \\
\hline Average & $85.5(27.9)$ & $96.2(28.9)$ & $131.0(26.4)$ & $124.1(26.9)$ & $203.9(45.3)$ & $175.5(43.3)$ \\
\hline
\end{tabular}

${ }^{1}$ If speakers 3 and 9 are removed from the model (see Table IV), the differ ence between geminate and singleton words in initial lengthening is still significant $\left(\beta_{\text {singleton }} \quad 5.23, \mathrm{SE} \quad 1.59, t \quad 3.37, p<0.01\right)$.

Baayen, R. H. (2008). Analyzing Linguistic Data. A Practical Introduction to Statistics Using $R$ (CambridgeUniversity Press, Cambridge), Chap. 6, pp. 181262.

Beckman, M. E. (1996). "The parsing of prosody," Lang. Cogn. Process. 11(1 2), 1768 .

Benguerel, A. P., and Cowan, H. A. (1974). "Coarticulation of upperlip pro trusion in French," Phonetica 30, 4155
Benner, U., Flechsig, I., Dogil, G., and Mobius, B. (2007). "Coarticulatory resistance in a mental syllabary," paper presented at the 16th International Congress of Phonetic Sciences (ICPhS), August 6 8, Saarbrucken, Germany. Available at www.icphs2007.de/conference/Papers/1017/ 1017.pdf (Last viewed 4/4/2016).

Bertinetto, P. M., and Loporcaro, M. (2005). "The sound pattern of Standard Italian, as compared with the varieties spoken in Florence, Milan and Rome," J. Int. Phon. Assoc. 35(2), 131151

Bybee, J. (2006). "From usage to grammar: The mind's response to repeti tion," Language 82(4), 711 733. Available at http://www.unm.edu/ jbybee/ downloads/Bybee2006FromUsage.pdf (Last viewed 6/4/2016).

Cho, T. (2004). "Prosodically conditioned strengthening and vowel to vowel coarticulation in English,” J. Phon. 32(2), 141176. 
Cho, T., and Jun, S. A. (2000). "Domain initial strengthening as enhance ment of laryngeal features: Aerodynamic evidence from Korean," UCLA working papers in phonetics, pp. 57 70. Available at http://escholarshi p.org/uc/item/2h69k4m7\#page 60 (Last viewed 4/4/2016).

Cho, T., McQueen, J. M., and Cox, A. E. (2007). "Prosodically driven pho netic detail in speech processing: The case of domain initial strengthening in English," J. Phon. 35(2), 210243.

Cholin, J., and Levelt, W. J. (2009). "Effects of syllable preparation and syl lable frequency in speech production: Further evidence for syllabic units at a post lexical level," Lang. Cogn. Process. 24(5), 662684.

Cunnings, I. (2012). "An overview of mixed effects statistical models for second language researchers," Second Lang. Res. 28(3), 369382.

Esposito, A., and Di Benedetto, M. G. (1999). "Acoustical and perceptual study of gemination in Italian stops," J. Acoust. Soc. Am. 106(4), 20512062.

Fougeron, C., and Keating, P. A. (1997). "Articulatory strengthening at edges of prosodic domains,” J. Acoust. Soc. Am. 101(6), 37283740.

Gili Fivela, B., and Zmarich, C. (2005). "Italian geminates under speech rate and focalization changes: Kinematic, acoustic and perception data," paper presented at the 9th European Conference on Speech Communication and Technology (INTERSPEECH), September 48 , Lisbon, Spain. Available at www.isca speech.org/archive/archive papers/ interspeech 2005/i05 2897.pdf (Last viewed 4/4/2016).

Han, M. S. (1994). "Acoustic manifestations of mora timing in Japanese," J. Acoust. Soc. Am. 96(1), 7382.

Hawkins, S. (2003). "Roles and representations of systematic fine phonetic detail in speech understanding," J. Phon. 31, 373405.

Hawkins, S., and Nguyen, N. (2003). "Effects of word recognition of syllable onset cues to syllable coda voicing," in Papers in Laboratory Phonology VI, edited by J. K. Local, R. A. Ogden, and R. A. M. Temple (Cambridge University Press, Cambridge), pp. 3857.

Hawkins, S., and Nguyen, N. (2004). "Influence of syllable coda voicing on the acoustic properties of syllable onset /1/ in English," J. Phon. 32(2), 199231.

Heid, S., and Hawkins, S. (2000). "An acoustical study of long domain /r/ and /1/ coarticulation," paper presented at the 5th Seminar on Speech Production: Models and Data, and CREST Workshop on models of speech production: Motor planning and articulatory modelling, May 1 4, Institut fur Phonetik und Sprachliche Kommunikation, Ludwig Maximilians Universitat, Munich.

Hsu, C. S., and Jun, S. A. (1996). "Is tone sandhi group part of the prosodic hierarchy in Taiwanese?,” J. Acoust. Soc. Am. 100(4), 2824.

Hussain, Q. (2015). "Temporal characteristics of Punjabi word medial sin gletons and geminates," J. Acoust. Soc. Am. 138(4), EL388 EL392.

Idemaru, K., and Guion, S. (2008). "Acoustic covariants of length contrast in Japanese stops,” J. Int. Phon. Assoc. 38(2), 167186.

Jun, S. A. (1993). "The Phonetics and Phonology of Korean prosody: Intonational Phonology and prosodic structure," Ph.D. dissertation, Ohio State University (Garland, New York, 1996), Chap. 6, pp. 226243.

Keating, P. A., Cho, T., Fougeron, C., and Hsu, C. S. (2003). "Domain ini tial articulatory strengthening in four languages," in Papers in Laboratory Phonology IX: Change in Phonology, edited by J. K. Local, R. Ogden, and R. A. M. Temple (Cambridge University Press, Cambridge), pp. 145163.

Kuznetsova, A. (2013). "Lmertest: Tests for random and fixed effects for linear mixed effect models (lmer objects of lme4 package)," R package version 2.029 , pp. 1 17. Available at https://cran.r project.org/web/ packages/lmerTest/lmerTest.pdf (Last viewed 5/4/2016).

Levelt, W. J. M. (1999). "Producing spoken language: A blueprint of the speaker," in The Neurocognition of Language, edited by C. M. Brown and P. Hagoort (Oxford University Press, Oxford), pp. 83122.
Levelt, W. J. M., and Wheeldon, L. (1994). "Do speakers have access to a mental syllabary?," Cognition 50, 239269.

Local, J., and Simpson, A. (1999). "Phonetic implementation of geminates in Malayalam nouns," paper presented at the 14th International Congress of Phonetic Sciences (ICPhS), August 1 7, San Francisco, CA. Available at www.internationalphoneticassociation.org/icphs proceedings/ICPhS1999/ papers/p14 0595.pdf (Last viewed 3/4/2016).

Loporcaro, M. (1990). "On the analysis of geminates in Standard Italian and Italian dialects," in Natural Phonology: The State of the Art. Papers from the Bern Workshop on Natural Phonology, edited by B. Hurch and R. Rhodes (Mouton de Gruyter, Berlin), pp. 149174.

Maddieson, I. (2013). "Syllable structure," in The World Atlas of Language Structures Online, edited by M. S. Dryer and M. Haspelmath (Max Planck Institute for Evolutionary Anthropology, Leipzig), Chap. 25. Available at http://wals.info/chapter/12 (Last viewed 5/4/2016).

Moll, K. L., and Daniloff, R. G. (1971). "Investigation of the timing of velar movements during speech,” J. Acoust. Soc. Am. 50(2B), 678684.

Nespor, M., and Vogel, I. (1986). Prosodic Phonology (Foris, Dordrecht), Chap. 6, pp. 165186.

Nguyen, N., and Fagyal, Z. (2008). "Acoustic aspects of vowel harmony in French," J. Phon. 36(1), 127.

Ohala, M. (2007). "Experimental methods in the study of Hindi geminate consonants," in Experimental Approaches to Phonology, edited by M. J. Sole, P. Speeter Beddor, and M. Ohala (Oxford University Press, Oxford), pp. 351368 .

Ohman, S. E. G. (1966). “Coarticulation in VCV utterances: Spectrographic measurements," J. Acoust. Soc. Am. 39(1), 151168.

Onaka, A. (2003). "Domain initial strengthening in Japanese: An acoustic and articulatory study," paper presented at the 15th International Congress of Phonetic Sciences (ICPhS), August 3 9, Barcelona, Spain. Available at www.internationalphoneticassociation.org/icphs proceedings/ ICPhS2003/papers/p15 2091.pdf (Last viewed 5/4/2016).

Payne, E. M. (2005). "Phonetic variation in Italian consonant gemination," J. Int. Phon. Assoc. 35(2), 153181.

Pickett, R. E., Blumstein, E. S., and Burton, W. M. (1999). "Effects of speaking rate on the singleton/geminate consonant contrast in Italian," Phonetica 56(3 4), 135157.

Pierrehumbert, J. B. (2001). "Exemplar dynamics: Word frequency, leni tion and contrast," in Frequency and the Emergence of Linguistic Structure, edited by J. Bybee and P. Hopper (Benjamins, Amsterdam), pp. 137157.

Pierrehumbert, J. B., and Talkin, D. (1992). "Lenition of $/ \mathrm{h} /$ and glottal stop," in Papers in Laboratory Phonology II: Gesture, segment, prosody, edited by G. Docherty and D. R. Ladd (Cambridge University Press, Cambridge), pp. 90117.

Pluymaekers, M., Ernestus, M., and Baayen, R. H. (2005). "Lexical fre quency and acoustic reduction in spoken Dutch," J. Acoust. Soc. Am. 118(4), 25612569.

Turco, G., and Braun, B. (2014). "Non local duration differences caused by consonantal length contrasts," paper presented at the 10th International Seminar on Speech Production (ISSP), May 5 8, Cologne, Germany. Available at www.issp2014.uni koeln.de/wp content/uploads/2014/ Proceedings ISSP revised.pdf (Last viewed $\mathbf{\square}$ ).

Turk, A., Nakai, S., and Sugahara, M. (2006). "Acoustic segment durations in prosodic research: A practical guide," in Methods in Empirical Prosody Research, edited by S. Sudhoff, D. Lenertová, R. Meyer, S. Pappert, P. Augurzky, I. Mleinek, N. Richter, and J. Schliesser (Mouton de Gruyter, Berlin), pp. 128.

West, P. (1999). "Perception of distributed coarticulatory properties of English /1/ and /r/," J. Phon. 27(4), 405426. 